\title{
Where's Social Work? A Critical Analysis of Gender Invisibility, Ethical Conflict, and Advocacy in Medical Teams
}

\author{
Roxanna Duntley-Matos \\ University of Michigan, matos@umich.edu \\ Robert M. Ortega \\ University Of Michigan, rmortega@umich.edu \\ Maria M. Matos \\ University of Puerto Rico, mariamatosupr1@yahoo.com
}

Follow this and additional works at: https://nsuworks.nova.edu/ijahsp

Part of the Medicine and Health Sciences Commons, and the Social and Behavioral Sciences Commons

\section{Recommended Citation}

Duntley-Matos R, Ortega RM, Matos MM. Where's Social Work? A Critical Analysis of Gender Invisibility, Ethical Conflict, and Advocacy in Medical Teams. The Internet Journal of Allied Health Sciences and Practice. 2020 Jan 01;18(4), Article 20.

This Concept Piece is brought to you for free and open access by the College of Health Care Sciences at NSUWorks. It has been accepted for inclusion in Internet Journal of Allied Health Sciences and Practice by an authorized editor of NSUWorks. For more information, please contact nsuworks@nova.edu. 


\title{
Where's Social Work? A Critical Analysis of Gender Invisibility, Ethical Conflict, and Advocacy in Medical Teams
}

\begin{abstract}
The traditional biomedical and person-in-environment (PIE) perspectives are often found in conflict when framed within broader gender discrimination and consumerist health care practices. Our critical feminist analysis addresses the case of Katie, a vulnerable health care recipient, whose intersecting identities fall outside of the "margins of acceptability." Communication deficits among team members and a lack of clear care protocols become evident. Insurance demands to justify coverage undermine the processes of beneficence and the ethic of care required for emancipatory advocacy. We present the tripartite paradigm of transformative complicity, cultural humility, and systems-based empowerment to address the complex ethical dilemmas that emerge. Strategies informed by experimental ethnography help us model effective transdisciplinary dialogue by inviting voices/commentators to rise from the margins (foot/endnotes) and decenter authorial power. Using an emancipatory social work framework, we offer actionable steps which, as revealed by our commentators, are often lacking from the medical team's and care recipient's toolbox. We call ffor discursive courage to chip away at the socially constructed myths of biological and moral deficit that merge gender, colorism, class, and invisibility in the web of historical and structural discrimination. In addition, we welcome service seekers, as therapeutic colleagues, in the process of systemic empowerment.
\end{abstract}

Author Bio(s)

ABOUT THE AUTHORS:

Dr. Roxanna Duntley-Matos is a cultural anthropologist and emancipatory social worker in community organizing and clinical practice. She has published in the areas of transnational community-based participatory action research, organizational justice, and ethical practice in higher education. She is the recipient of the University of Michigan Circle Award for bridging academia and the broader communities through excellence in transformative education, the ABSAME Rogues Jane Addams Scholarship from the Heart Social Justice Medallion, and the MI Hispanic/Latino Commission's Top 50 Latinas of Michigan Recognition. She is the former President of the Organization of Latino Social Workers, Michigan Chapter, a former board member of the Ml Children's Trust Fund for the Prevention of Child Abuse and Neglect, designated by the Governor, and a former board member of the Association of Behavioral Sciences and Medical Education.

Dr. Robert M. Ortega is Associate Professor, the University of Michigan School of Social Work. He has written in the areas of child welfare, health and mental health, and culturally responsive practice. His current research focuses on child welfare workforce, social justice in groups, and culturally responsive practice. He is the recipient of numerous national awards including the 2013 Recent Distinguished Contributions to Social Work Education Award, the University of Michigan Circle Award, the Lisa Putnam Award for Excellence in Child Welfare, the ABSAME Rogues Jane Addams Scholarship from the Heart Social Justice Medallion, and the Organization of Latino Social Workers, MI Chapter Lifetime Achievement Award.

Maria M. Matos is a retired Professor from the University of Puerto Rico, Rio Piedras campus. Her academic interests are in General Studies and American Literature with a specialization in William Faulkner's use of time. Her awards include the Instituto de las Españas Medal for her critical analysis of Don Quijote de la Mancha, and the University of Puerto Rico Teodoro Aguilar Gold Medal recognition leading to her Harvard University full scholarship Masters Degree, She also received an Honorary Doctorate Designation by the Puerto Rican Board of Higher Education, Offices of Licenses and Accreditation, for her 
extraordinary work as President of the Consulting Board and for her contributions to Puerto Rican Higher Education.

\section{Acknowledgements}

A primary inspiration for this article lies with our dear colleagues from the former Association of Behavioral Sciences and Medical Education (ABSAME), co-directed by compassionate NSU humanists and outstanding transdisciplinary educators and scholars: Dr. Stan Cohen (co-founder), Dr. Patrick Hardigan (ABSAME former director), and Dr. Kathleen Hagen (ABSAME former Board of Director, outstanding musician, and transformative educator). Other highly supportive colleagues include Ms. Laurel Humbert (former ABSAME Vice-President), Dr. Don Self (former ABSAME journal editor), and Dr. Fred Hafferty (ABASME Board member. Our "familia academica" affiliated (past or present) to the University of Michigan, Ann Arbor: Dr. Lorraine Gutierrez, Dr. Norbert O. Ross, Dr. Charles Garvin, Dr. Linwood Cousins, Dr. Ruth Dunkle, Dr. Laura Lein, Dr. Steven Applewhite, and Dr, David Brose have been profound inspirations. The spirit of our social work students from various institutions, highlighting NASW Student of the Year Cindy Newberry, shines in this work as well. The unique contribution of our work could not be accomplished without the support of our authorial decentering "voices from the margins" (in alphabetical order): Alexandra Cubero-Matos (anthropology, conservation ecology, and animal behavior student), Daniel Cubero-Matos (musician and community philosopher), Dr Parul Sud, MD (Program Director of the Internal Medicine Residency Program at McLaren Hospital in Flint, MI), Ms. Dalia Reyes (Our Lady of Guadalupe Parish member, Flint, MI), and Dr. Odeather Hill, LMSW, PhD (Founder and President of Deaf Matters, Inc.). We would also like to thank Dr. Cheryl Hill, editor of the Internet Journal of Allied Health Sciences and Practice and the reviewers of our article for their thought provoking comments. Finally, our work would no have been possible without the technical support of Mr. Sean Hennessy. 


\title{
IIJAHSP \\ The Internet Joumal of Allied Health Sciences and Practice \\ Dedicated to allied health professional practice and education \\ Vol. 18 No. 4 ISSN 1540-580X
}

\section{Where's Social Work? A Critical Analysis of Gender Invisibility, Ethical Conflict, and Advocacy in Medical Teams}

\author{
Roxanna Duntley-Matos ${ }^{1}$ \\ Robert M. Ortega ${ }^{1}$ \\ Maria M. Matos ${ }^{2}$ \\ 1. University of Michigan \\ 2. University of Puerto Rico \\ United States
}

\begin{abstract}
The traditional biomedical and person-in-environment (PIE) perspectives are often found in conflict when framed within broader gender discrimination and consumerist health care practices. Our critical feminist analysis addresses the case of Katie, a vulnerable health care recipient, whose intersecting identities fall outside of the "margins of acceptability." Communication deficits among team members and a lack of clear care protocols become evident. Insurance demands to justify coverage undermine the processes of beneficence and the ethic of care required for emancipatory advocacy. We present the tripartite paradigm of transformative complicity, cultural humility, and systems-based empowerment to address the complex ethical dilemmas that emerge. Strategies informed by experimental ethnography help us model effective transdisciplinary dialogue by inviting voices/commentators to rise from the margins (foot/endnotes) and decenter authorial power. Using an emancipatory social work framework, we offer actionable steps which, as revealed by our commentators, are often lacking from the medical team's and care recipient's toolbox. We call for discursive courage to chip away at the socially constructed myths of biological and moral deficit that merge gender, colorism, class, and invisibility in the web of historical and structural discrimination. In addition, we welcome service seekers, as therapeutic colleagues, in the process of systemic empowerment.
\end{abstract}

Keywords: gender, ethical conflict, medical teams, transformative complicity, cultural humility, empowerment

(Editor's note: There are citations/references and footnotes in this manuscript. The footnotes are indicated by alpha characters and are enclosed in superscripted brackets. The text of the footnotes is printed immediately after the reference list.) 


\section{INTRODUCTION}

As medical education moves toward the provision of a more personalized attention, it is devising ways to integrate humanistic curricula such as literature, the arts, music, philosophy, history, and cultural anthropology. Such efforts aim to promote compassionate treatment for those in need by sharing perspectives that will lead to complex understandings of illness and healing. These advances, however, continue to exist within a harsh reality of for profit insurance exclusionary practices. They are often couched in less than visible patriarchal ideologies that continue to permeate medical and social services, while purporting to safeguard the wellbeing of all care seekers.

The increasing call for compassionate and culturally-responsive interdisciplinary teams reflects the profound practice concerns that saturate health care provision and service recipient relationships. ${ }^{1}$ Efforts that claim to address the limitations of professional hierarchies and of biomedically limited discourses continue to have deficits in implementation. They reflect an inattentiveness to the experiences of care recipients and practitioners who live and struggle with inconsistent or less-than-adequate accessibility due to economic hardship and social marginalization. ${ }^{1}$ In addition, ethical clashes arise from siloed professional perspectives that are embedded within damaging relations of power and subordination. Discord occurs between practitioners and institutions, practitioners themselves, and all of these and their care recipients. A critical analysis of these challenges enables us to see this more clearly when we provide emancipatory spaces for marginalized voices to arise and question us from within our texts. [a]

\section{EXPERIMENTAL METHODS, THEORETICAL FRAMEWORK, AND DISCURSIVE COURAGE AS PRAXIS}

Modeling the dialogic processes and the dimensions of inclusion that we recommend requires employing critically intersubjectively engaged ethnographic strategies (CIEE). These are informed by cultural studies, critical feminism, and experimental ethnography. ${ }^{3-4}$ Through CIEE, we invite readers from different cultural, gendered, ethnic, phenotypic, and professional identities to comment from the margins (via foot/endnotes) and disrupt traditional academic hierarchies. These voices are located after the References section of this article.

Through CIEE, our interpreters ultimately engage the primary authorial and authoritative presences to enrich and decenter ideological assumptions in the text. Such exchanges are what we propose for interdisciplinary teams that aspire to prioritize an ethic of inclusion, collaboration, and mutual care. Similarly, we offer a different take on "translational science" to improve accessibility to information and good health outcomes. It is commonly believed that when social or natural scientists refer to translational science, the simplest language must be used to communicate with a broad audience to increase the likelihood of implementation and positive impact. In the spirit of Paulo Freire's liberation pedagogy, however, we find great value in providing theoretical and technical language access to the general public. ${ }^{5}$ Doing so promotes multi-sector advocacy skills that demonstrate effectiveness across traditionally exclusionary boundaries. In this way, dependence on those who hold academic positions of power is diminished as equitable collaboration is strengthened. ${ }^{[[b]}$ The importance of similarly skilled communication across hierarchies cannot be overemphasized. Our analysis of the medical case we have chosen reveals how truly prevalent it is for healthcare practitioners and service seekers to find themselves at an ethical and moral loss when they are disengaged from a critical communicative process. Awareness of this is especially important when there are multiple care needs, a need for shared language and, most importantly, shared advocacy skills.

The person-in-environment (PIE) social work perspective, is also foundational in our work. It enables us to offer principles and exploratory questions that help team members frame service provider and user needs within personal, institutional, and political contexts. The tripartite paradigm of transformative complicity, cultural humility, and empowerment is the primary vehicle for accomplishing a humane trans-professional understanding, institutional transformation, and responsive care from a critical social work and feminist lens. 1, 3-13 The Four Pillars, which we refer to here as the Four Pillars of Healing and Resilience (safety, support, trust, and hope), provide the basis for the healthy and compassionate communication needed in teamwork in general. ${ }^{14}$ Our preference for cultural and ethnic identifiers (that deconstruct racialized sociocultural imaginings) follow anthropological perspectives (cultural and biological) supported by genetics. In this sense, we employ discursive courage by making apparent the impact of colorism (color-based discrimination) on care-seeker (in)visibility. ${ }^{1}$ Discursive courage refers to the courage to use terms that reflect what we know from science at this time: human beings are not made up of different "races" and we do not fit in five color categories which originated in colonialism and slavery. Colorism, commonly depicted as "racism" by the media, academic researchers, politicians and the general public, is historically and culturally situated. It is time we exhibited the courage to call it what it is so we have a better chance of combatting phenotypic profiling and its accompanying harms.

Our investment in bridging theory to praxis honors an individual and community empowering perspective. ${ }^{11}$ To this end, we move from a primarily academic discussion to a delineation of actionable steps and strategies. We highlight our theoretical and practical emphasis in the following case example: 
KATIE: ADAPTED FROM "TRUTH, TRUST, AND TEAM PLAY" BY ALAN ZENAKIS, M.D. 16

Katie is a 47-year-old breast cancer awareness specialist who we can presume is heterosexual and of light complexion (based on the lack of phenotypic, cultural, and sexual orientation description in the original case). Her actual cultural lineages are impossible to discern. The limited allusion to her intersectional identities, however, does challenge the standard assumptions and protocols of institutionalized medicine on many levels. Ironically, her status as a cancer specialist does not preclude factors that put her in the "at risk" category for the disease or prevent her from experiencing bureaucratic constraints that are triggered by other aspects of her identity. This becomes evident when she requests to undergo preventative diagnostic testing. Because of her closed adoption process as an infant, she lacks a documented medical history that is required by the insurance company to pay for her evaluation. Katie faces further complications due to her prior elective breast implants, which make standard mammograms unreliable and add expense to her treatment. Her gynecologist prescribes genetic testing and an extended mammogram, leading to increased scrutiny and the revelation of cultural and bureaucratic complexities. To qualify her for coverage, her doctor submits unsubstantiated medical information. This leads the insurance company to believe that Katie has a family history of cancer. His actions trigger a series of moral and ethical dilemmas which pose a quandary for team members. The problem of how-to best address Katie's medical needs becomes complicated by what the gynecologist believes to be the best response to a potentially life-threatening condition from a medical ethics perspective.

\section{Team Dynamics: Challenges and Strategies for Effective Care}

The trials and tribulations of multidisciplinary health-team service provisions are well established in the literature[c] Fragmentation, hierarchy, authoritarianism, and elitism are common as a result of a lack of training in interdisciplinary communication, a dearth of support for institutional systems, and poor funding for interventions required to subsidize more time-consuming enterprises such as collaborative dialogues. Katie's case reflects how challenges between team members operate within conflicting ethical perspectives for participants. In her story, a nurse, a public health professional, a male gynecologist, the patient, and the insurance company are the primary players. A social worker is not considered. This leads the reader to envision a traditional medical team. The insurance company, in its role as a distant team partner, maintains considerable influence over what medical attention can be entertained.

In the following sections we explore the underlying assumptions often found in traditional biomedical teams. We address their impact on ethical decision-making outcomes within institutional and consumerist protocols that continue to be guided by shapeshifting benevolent-paternalistic ideologies. We consider the impact of these processes on team interactions in Katie's case by examining the acceptability of her current needs determined by social access. Finally, we conclude by addressing two concerning systemic repercussions that iterate the invisibility and gender-exploitative dynamics permeating and, reciprocally maintaining, local and global levels of influence. It is necessary to appreciate how judgements about Katie's identities (i.e. her past status, her decisions, and current social position) affect her trustworthiness from the perspective of those who hold power over her.

\section{Who Is Consulted? The Politics of Communication and Ethical Outcomes}

The process of consultation in teamwork is central to effective communication. In Katie's case, who is involved in the conversation is important to consider, but difficult to discern. Purportedly, "after some [unspecified] deliberation," the gynecologist, prioritizing Katie's patient status above any other identity, tries to secure medical services given that her risk for cancer could be as high as $80 \% .{ }^{16}$ Without a medical history, he fears that the insurance company will deny reimbursement. Consequently, he decides to offer unavailable information about her history to the insurance company. Faced with his actions, the public health specialist and the office nurse face a dilemma between professional ethics of care (which prioritize the welfare of the care seeker) and the ethics of institutional accountability (which prioritize financial gain of the insurance company and service providers). The team members struggle with unstated issues of loyalty to the doctor (their "superior"), and concern for their own welfare (as "subordinates") if they are found to be guilty of misrepresentation. Less explicit in the case are the insurance company's financial interests.

\section{Identifying Contradictions: Ideals vs Practice(s)}

Distinguishing between ethical ideals and actual practices enables us to identify harmful misalignments, misconceptions, and potential steps for resolution from a transformative complicity perspective. Ideally, Katie's procedure would begin with an empathetic critical dialogue leading the team to consider its values and judgments regarding body-altering procedures for cosmetic reasons. The team would address the impact of the procedure on other care seeker characteristics, the role of stigma towards women and towards adoptees. It would consider how these might influence power dynamics in the relationship between Katie, themselves as team members, and the insurance company. ${ }^{17}[\mathrm{cl}$ Instead, a fragmented team confronts the power of imposed genealogical medical documentation over Katie, which leaves her subject to bureaucratic decisions.

The insurance company is depicted as a coherently bound system that is neutral, unapproachable, authoritarian, and intractable. In the medical office, the nurse and public health professionals are in a similar position of subordination vis à vis the gynecologist, 
leading the decision-making processes to be less than collaborative. Despite the nurse's and public health specialist's concerns about the gynecologist's ethics, neither one of them exhibits the necessary moral courage to address the problem raised in disclosing insufficient information. Instead, the nurse considers imposing the burden of communication with the doctor onto Katie, assuming that the trustworthiness of the gynecologist will be compromised if she finds out about his report.[d] Consequently, the nurse and other team members must confront the dilemma of whether or not to disclose such practices to the care recipient and to the insurance company.

The coercive dynamics exercised by the health professionals on Katie may also be influenced by stigma because of her adopted status. This issue is compounded by judgmentalism about her prior breast enhancement surgery, found to be a complicating factor in her diagnosis. Cultural values that prioritize biological lineage, and which perceive female decisions about body image as frivolous, have implications for notions of acceptable family and individual worth in the current for-profit health system. As stated by Peters in Politics and patriarchy: Barriers to health screening for socially disadvantaged women, these concerns must be considered in determinations of service recipient rights and insurance policies. ${ }^{18}$ Decisions about priorities over health coverage are often framed as "value free" in a context of reasonable expense that, in effect, disregard professional and gendered subordinations that increase health disparities and cost. Katie, as an adopted and presumably economically vulnerable woman, serves as an example of how people of perceived lower status often become negatively targeted by deficit-based policies. ${ }^{19}$ As evidenced in this case, such policies impose detrimental eligibility criteria and simultaneously put care seekers at increased disadvantage and life threatening risk.

\section{Worth or Worthiness: The Question of "Objectivity" and Body Politics}

Katie's experience of being examined from a deficit perspective raises the issue of worth and worthiness. Worth, as used in our analysis, is defined as a an "objectively" agreed upon value such as that of a nickel, which is "worth five cents" and to socially predefined positions associated with higher revenue making skills and status (i.e. medical doctors compared to nurses and nurses to social workers). Worthiness, on the other hand, is more clearly a relational value. ${ }^{20}$ It has less to do with monetary significance or social status and more to do with implied "merit" and "deservingness" based on a person's caring character and interpersonal accomplishments. It is common, as revealed in Katie's case, for these two concepts to be conflated from an institutional perspective so that the lack of economic worth becomes a determinant of worthiness. In capitalism, lack of financial value tends to be equated with lack of personal, community, and cultural deservingness leading to epithets such as lazy, dependent, lacking in initiative and skill, and diminished intelligence.

An anti-oppressive feminist perspective, however, leads us to explore these discursive nuances and interwoven practices to ask the following questions: "Does Katie have the merit and value in the eyes of her nurse, public health professional, and insurance company to be treated the way the physician is recommending?" On the other hand, "What does her invisibility within insurance policies imply about her worth and worthiness from their perspective?" "Can insurance policies be assumed to be unbiased and equitable and should they be left unscrutinized when they perpetuate the exclusion of individuals who already suffer from a general lack of recognition?"

Katie's experience is emblematic of a society that continues to struggle with gender equity and women's rights over their bodies as well as self-determination, even when economic status is not considered. Perceived objectivism and the reduction, exclusion, and/or simplification of complicating variables serve to obscure hidden dynamics of health provider power. As revealed in the following quote by Kessler, limitations on women's rights are defined as value free, medically objective, and reflective of society's general sentiment of entitlement over women's bodies. ${ }^{21}$

...The clearest demonstration of...social consensus comes from our policies regarding health insurance. In almost any context, the treatment of cancer - and usually reconstruction after mastectomy - is covered as a medical benefit by insurers... It makes little sense for the FDA to consider breast augmentation of equivalent importance with an accepted component of cancer therapy (par 10)...These restrictions on the use of silicone-gel implants for breast augmentation are not based on any judgment about values...In the end, it comes down to the risk-benefit ratio...(par 12)

.... It has become fashionable in some quarters to argue that women ought to be able to make such decisions on their own. If members of our society were empowered to make their own decisions about... products for which the FDA has responsibility...then the whole rationale for the agency would cease to exist....(par 13) The FDA was established as a result of a social mandate.

...Manufacturers have vested interests. Between those interests and the interests of patients, the FDA must be the arbiter...To argue that people ought to be able to choose their own risks, that government should not intervene, even in the 
face of inadequate information, is to impose an unrealistic burden on people when they are most vulnerable to manufacturers' assertions...Those are...the situations in which the legal and ethical justification for the FDA's existence is greatest... The decision about breast implants reflects that need. (par 14) [e]

Kessler's indictment reveals how the power and assumptions about scientific objectivity are so ingrained in medicine that even when subjectivity is acknowledged, as is done in his opinion, the framing of his words (as a Federal Drug Administrator (FDA), imbues him with authority and presumptions of truth. His 1992 defense of the FDA's right to determine whether women can make their own choice to have cosmetic breast augmentation (outside of the context of cancer related mastectomy) reveals concerning generalizations that manifest as mechanisms of control present to this day. ${ }^{21}$ (par: 10-14)

From a body-politics, and critical feminist perspective, Kessler's arguments perpetuate the image of women as naive and in need of the FDA's protection from being manipulated by drug advertisement campaigns. ${ }^{21-22 \text { [f }}$ His argument offers a paternalistic perspective of women's health that essentializes and infantilizes them. It moves us away from the person-centered calling of health and social service professions. In other words, Kessler constructs his subjectivity as "objectivity" and as a "social mandate" without defining who has the authority to speak for society and who has the right to be heard within it. Kessler defines his perspective as an "ethical justification" for the FDA's existence; one that prioritizes a risk/benefit ratio and which, according to him is not a value.

Katie's case is an example of how the effects of Kessler's and the FDA's views on deservingness inform actual policy practice. Her case essentially asks health professionals to consider whether women are worthy of receiving preventative care in the context of their decisions to alter their bodies. It leads us to think of the processes that result in potentially harmful effects for the care seeker and to consider what changes need to be made. It also offers an opportunity to challenge a system that is designed to provide minimal and largely undifferentiated services to a male centered, massified, and politically controlled society. As stated by Shim,

... [color], class, and gender must be re-conceptualized as social relations of power that are located not just in the biological bodies of individuals but in the social spaces between them, producing and stratifying the distribution of health and illness. ${ }^{23}$

\section{Rationality and Body Altering Decisions: Countering a Benevolent Patriarchal Perspective}

Kessler's comments about the ability of women to make rational and well-informed decisions are consequential. Recent research states, "Breast augmentation is associated with high service recipient satisfaction and significant improvements in quality of life."24 The implications are serious; women's cosmetic choices over their bodies have an important effect on self-esteem and emotional health. However, Kessler's original indictment (now over two decades old) still reflects current insurance company practices that exclude women. Most will not cover breast augmentation for cosmetic reasons. ${ }^{25}$ This finding leads us to other important questions: Who decides what "evidence based" research will be accepted to inform policy and under what conditions? What "evidence based" research do we draw upon, actively ignore, or remain ignorant of, in our efforts to perpetuate the idea of "value-free" policies? Whose benefit is prioritized in the FDA's calculation of risk: The women, the insurance companies, or the pharmaceuticals?

\section{Deconstructing Biological and Family Determination: The Role of Beneficence}

Katie's case alludes to other levels of oppression that point to taken-for-granted patriarchal ideals of nuclear family lineage that are inherently associated with colorism and social status distinctions. The assumption that all service seekers have biological medical histories is based on a specific socio-cultural and economic perspective of the family. ${ }^{27}$ This is inherent to Western society, but is also being increasingly challenged in global migratory and transculturation studies. ${ }^{26}$ As discussed by Tam, Findlay, and Cohen, it is important to explore the concept of family and its use in current institutional definitions. Its manipulation by insurance policies and its impact on social relationships is highly salient. ${ }^{27}$

The values and evidence-based assumptions underlying the biomedical model, which continue to be portrayed as neutral, need to be actively addressed in interdisciplinary and interprofessional teams. ${ }^{1}$ Interrogating the cultural limitations of our health systems can lead us to offer a practice-oriented paradigm that more effectively promotes beneficence, ethical decision-making, and personcentered care. This, in turn, can lead to valuing the dignity and worth of all team members, especially the care recipient, and to implementing more compassionate institutional policies and practices. Beneficence, as discussed by Robinson-Bailey, is:

... [treating persons] in an ethical manner[,] not only by respecting their decisions and protecting them from harm, but also by making efforts to secure their well-being... The term "beneficence" is often understood to cover acts of kindness or charity that go beyond strict obligation. In this document, beneficence is understood in a stronger sense, as an obligation. ${ }^{24}$ Two general rules have been formulated as complementary expression of beneficent actions in this sense: (1) do not harm and (2) maximize possible benefits and minimize possible harms (The National Commission 1979). ${ }^{28}$ 


\section{Ethical Fragmentation in Katie's Team}

Theoretically, beneficence, as opposed to harms, is the primary value for Katie's team and should be for the insurance company. However, as discussed, the only one who truly follows this value appears to be the doctor. Ironically, by ignoring his colleagues, his decision promotes animosity towards him and undermines the socially sanctioned hierarchical order which he represents and which his team respects. His inability to share power with his colleagues weakens the possibility of a democratic process, which would be more emblematic of the caring value of the profession and the one he is presumably upholding with his care seeker. Ultimately, the traditional biomedically and insurance-focused process of this case defeats its own primary goal to protect health and life as it presents multiple levels of invisibility that make Katie unworthy from an insurance perspective.

\section{Transformative Complicity, Cultural Humility, and Empowerment: A More Transparent Beneficent Approach}

Current scholarship on servant leadership in the medical profession is moving more and more towards transparency, trust building, validating collaborations with energizing and healthy interprofessional teams that are financially viable. ${ }^{1,29}$ For this to occur, however, critical self-reflection that is action- and transformation-focused is paramount. The processes of transformative complicity, cultural humility, and system-based empowerment are highly relevant in this regard.

Transformative complicity is both a theory and an ongoing process that challenges and enables team members to address the dynamics that reveal our past and present unwillingness to examine the intersections of power and subordination within each of us and between us and our institutions. 1, 4-8 Facing our own participation in injustice, when we believe ourselves to be good and ethical people, moving beyond denial and guilt into action, tracking our harms, having courage, taking calculated shared risks, and making sacrifices that may lead to institutional punitive measures, are imperative. 1, 4-8, 30 This is especially clear in the hierarchical and discriminatory policies, practices, and views often found in neoliberal society.

Transformative complicity embraces feminist standpoint theory, which argues that "identity is socially constructed through historical context and processes that are fluid, dynamic, and interdependent."13 These conditions create different perspectives depending on the combination and influences of the social locations embodied by each person in relation to the environment and to the dynamics of power that their locations represent. Cultural humility, the first tenet of transformative complicity, urges us to think of the epistemic privilege or experiential wisdom of those with whom we interact.9-10 It prioritizes an appreciation of their and our multidimensionality and intersectionality in our effort to be aware that we know very little of what there is to be known and to remain open to all that we might learn. It is a difficult and ongoing journey.

The purpose of cultural humility is to provide caring support through validation and continued empathic exploration in a way that will reduce hierarchies between team members and between them and their institutions. Thus, our tripartite paradigm emphasizes an awareness of our own participation in institutional oppression. It stresses an active reflective self-analysis so that we, as social change agents, will have the courage and skill to question the limitations of our knowledge, reduce our harms and humanize our institutions. In essence, it seeks to make us aware of both our congruent and incongruent practices resulting from embodied levels of privilege and subordination.

This transformative complicitous process promotes creative thinking among team members. It encourages solutions that may push the boundaries of current insurance and institutional policies by working in the gray areas and between the contradictions in discourses boasting person-centeredness that mystify embedded exclusionary practices. It asks team members to employ patient impatience to address the demands of their superiors, the insurance company, and participant needs. It asks them to track [the] harms that might result from their interventions. ${ }^{1-2,4-8,30}$

Deciding what might cause more good than harm is central to prioritizing the well-being of the service recipient over the needs of the medical market. As consumers, it behooves us to consider how socio-political and economic priorities guide health care benefits to understand who is (and is not) deemed eligible and worthy of life enhancing and life-saving services. We must critically explore what assumptions are made of different groups if we are to promote social justice. Once this analysis is completed, the team is better able to move from denial and guilt into action and participate in calculated shared risk.1, 4-8 Our application below demonstrates how this might be accomplished.

\section{Transformative Complicity Applied to the Team's Ethical Dilemma}

In Katie's case example, the gynecologist, through his conversation with Katie, attempts to adapt and respond to her needs. His report to the insurance company has the potential of disclosing Katie's lack of medical history, which might make assessing her vulnerability to, and timely treatment of, breast cancer impossible. By trying to thwart exclusionary policies, he abides by his most significant ethical code: that of prioritizing Katie's wellbeing. However, his primary error figures in the exclusion of his team members 
from the decision-making process. Regarding power and subordination, his power rests in his ability to determine the best way to uncover Katie's health risk and to decide who is included (and excluded) in his communication network. His own position of subordination is apparent in his dependence on professional credibility and validation from his superiors (absent in the case example) and the insurance company. It is revealed in his lack of transparency when responding to insurance demands.

By neglecting his team members, he re-inscribes the hierarchical dynamics of his professional training as well as those of the hospital and the insurance company which he is trying to combat for Katie's sake. ${ }^{1}$ The practice of cultural humility, especially as it relates to an awareness of epistemic privilege and intersectionality resulting from critical self-reflection, openness, and transcendence, is completely absent. The service providers are unable to reduce the power differentials between them, between them and Katie, and between them and the insurance company. They are, in the end, left in a more vulnerable state that maintains the passive-aggressive discord that surfaces in their lack of interaction.

The behavior of the gynecologist's nurse is revealing in this regard. She is more concerned about Katie's ability to trust her doctor's loyalty to institutional protocols than she is about the equity of the policies and the potentially life-saving treatment that Katie needs. The values of person-centeredness, in effect, conflict with the status she derives from representing the hierarchical protocols of the profession. Her subordination to the gynecologist (her "superior") becomes more apparent as her power over the care seeker, whom she deems less knowledgeable, easily manipulated, and (therefore) inferior is enacted.

From this stance, the nurse is unable to examine her own biases and insecurities as they relate to the exclusions experienced by Katie. She is unable to become aware of how insurance policies are contradicting the ethical mandates of her profession. Thus, she redefines and transforms the doctor's mandates of beneficence into accusations of professional violations that put Katie's health, the gynecologist's credentials, and the reputation of their institution in danger.

The principle of beneficence ultimately becomes the object of misguided and self-enhancing interpretations. As a result, many critical socio-political and economic processes (that are necessary for effective service provision) fail to occur and lead to the difficulties experienced by the team. The potential for successful concerted action that could result in a policy adjustment for Katie (and others like her) is ultimately thwarted.

From a transformative complicity perspective that values beneficence, however, the calling to protect Katie's health should be first and foremost for the nurse and public health professional. Their responsibility is to arm themselves with courage, participate in shared calculated risk, and request a meeting with the gynecologist to discuss how to best protect her rights to treatment. It is at this point that the medical practitioners should ask themselves who should be included in their team to ensure their ethical and moral calling. An objection that has been levied against transdisciplinary models has been the "time-money ratio" and the consequences of quality treatment for a reduced number of patients. According to Duntley-Matos, Shiery, Ortega et al, however, effective preventive care practices with these teams actually improves general health, reduces recurrent hospital visits, and decreases overall expense. ${ }^{1}$

\section{Emancipatory Social Work as a Facilitator of Culturally Responsive Transprofessional Communication}

As revealed in our prior discussion, determining team composition is central when communication dynamics are ineffective and are harming the best care for the service seeker. In Katie's case, it becomes evident that a social worker, appropriately educated in systems practice and transformative complicity, can mediate between team and insurance company priorities. The steps to promote a democratic engagement initiate a deconstruction of benevolent-patriarchal dynamics and highlight the centrality of Katie's voice and needs. The team members, by sharing their mutual knowledge equitably, are more likely to reach an empowering and solution-focused dialogue with each other and with the various institutions that are connected to Katie.

The social worker, in conjunction with the team, would need to consider the strategies required to promote systemic change. For instance, approaching the insurance company in an adversarial manner might lead to a lack of transparency from all sides in the spirit of self-interest. Working as a team that benefits from the emancipatory social worker's systems knowledge and experience, however, could be the first step to promote a viable solution for Katie's dilemma; one that could bring light to the unidentified needs of others who find themselves in similar circumstances. In addition, when the tripartite paradigm is actively used in collaborative teamwork, participants are more likely to foster a truly person-centered dialogue between the care recipient, the team, and the insurance companies. The Four Pillars of Healing and Resilience (safety, support, trust, and hope) are enacted..$^{14}$ Increased trust, transparency, and a reduction in ethical concerns facilitate empowerment at the personal, interpersonal, and political levels. ${ }^{11}$

At the personal level, it enables the practitioner to feel increased self-esteem, which facilitates self-assurance and courage to face ongoing and future challenges. At the interpersonal level, it fosters team communication, critical analysis, and action. At the political 
level, it promotes systemic transformation that will be more responsive to the needs of historically neglected populations. As stated in 1991 by Gutierrez and Ortega, the goal of social work practice is:

...not to adjust or accept problems, but to help [us] develop the ability to change the situation or prevent its recurrence...Because the effects of powerlessness occur on many levels, efforts towards change are directed at both individuals and institutions. ${ }^{11(p .25)}$

Social workers, when educated in transformative complicity, become immersed in critical thinking and experiential activities in transdisciplinary contexts.[g] The primary purpose of their decision-making endeavor is the care recipient's wellbeing. Such practitioners contribute to a beneficent systems-focused praxis in a medical team by facilitating an engaged and culturally humble critical analysis. ${ }^{9-10}$ They promote effective interventions at all levels. ${ }^{11} \mathrm{~A}$ social worker who is educated in this way can facilitate the attainment of concrete emancipatory goals through power-decentering exploratory questions. ${ }^{2,19}$ As we move from a multidimensional ethical analysis to a process of intervention, the following actionable steps and questions become powerful advocacy tools. ${ }^{[h]}$ Although these may seem obvious to some health providers, given the comments of our voices from the margins (foot/endnotes), it is clear that these strategies are absent in the experiences of many vulnerable care seekers.

\section{Exploratory Question (EQ):}

1. Determining the participants in the team:

EQ: Who should participate in a team to ensure the best holistic care, advocacy, and resources for a care recipient?

2. Inviting a discussion about the multiple perspectives that exist in the group.

$\mathrm{EQ}$ : How can a democratic dialogue that is inclusive of all voices be ensured?

3. Assessing whether the policies, procedures, and practices recognize their limitations and consider changing knowledge and information.

EQs: Are the insurance and other healthcare policies equitable? How do they relate to our mandates as providers to promote the best care, advocacy, inclusive practice, and social justice for our service seekers and others like them? What does evidence-based research designed by historically under-represented scientists tell us about the importance of different perspectives pertaining to culturally responsive medical care?

4. Addressing power differentials and ensuring culturally responsive approaches to service delivery.

EQs: What identity-based power and subordination dynamics take place at the various levels of our society and in the medical decision-making process more specifically? How do these dynamics relate to the cultural awareness, knowledge, skills, and blindness exhibited by the team members as they judge worthiness, justifiability, information framing, and service provision?

5. Considering the generalizability and transferability of the decision-making process to the medical needs of other members of society.

EQ: What are the implications or effects of our decisions on the care recipient and the broader socio-political system when we create awareness of the needs of similar individuals?

6. Advocating for service provision when eligibility criteria unjustly disadvantage a disproportionate number of care seekers from underrepresented groups.

EQ: What steps can we follow in our advocacy efforts when the insurance company appears to be inflexible or exclusionary?

\section{Emancipatory Social Work Advocacy Steps to Consider with Insurance Companies}

When confronted with ethical dilemmas that pit welfare against insurance economic interests, moving from guilt and denial into action, a component of transformative complicity, requires providers to find concrete ways to prioritize the pressing needs of their care seekers. ${ }^{1-4-8}$ This implies including individuals from various professions who are skilled in transcultural and transprofessional dialogue, including advocates that represent the intersectional identities of the care seeker. It also implies having protocols that include the service recipient in the advocacy effort. Melanie Haiken, Senior Editor of caring.com (https://www.caring.com/authors/melanie-haiken), offers advocacy tools, which are absent in Katie's case, but which are significant in emancipatory social work. ${ }^{31}$

1. Get help from social workers, patient advocates, and case managers. [Hospitals, clinics, and insurance companies often have some].

2. Get [the] insurance company to assign a case manager. [This puts the service recipient on their radar when they are needed...]. 
3. Find out as much as [possible] about...coverage and... the gaps... [Understand the difference between co-pays, coinsurance, deductibles, and insurance caps].

4. Keep detailed records.

5. Act early and often. [Address questions or decisions that seem unfair immediately. Write down the name and the title of the insurance representative. Take notes of all that is said with appropriate dates. Make sure that [the] doctor codes all medical procedures appropriately].

6. Don't give up in frustration. [For care seekers who are socially vulnerable (i.e. low literacy levels, overwhelmed due to illness and socio-economic poverty) find an advocate to assist them].

7. Read the success stories of...cancer patients who have won the insurance game.

\section{CONCLUSIONS}

The interactions between practitioners, medical care recipients, insurance companies, and national health policies are hardly ever simple. They function within a broad value-informed framework called culture(s), which is constantly challenged by the multiple, fluid, and clashing sub-cultural dynamics emanating from differing positions of power and subordination in a treatment team. In addition, they are connected through the market on a global scale that perpetuates unscientific "racialized" phenotypic misrepresentations (stereotypes).

Hierarchies of power are enforced by decision-makers in positions of economic and social privilege in a consumer-driven society ruled by a continuously shape-shifting patriarchal ideology underlying our medical institutions, beliefs, policies, and practices. This is evident in traditional biomedicine which continues to be gender biased, emphasizing authoritarian expertise that tends to exclude and invalidate the various voices that are inherently part of health seeker care. ${ }^{32}$ Examples of service recipients being told what to do and how to feel, regardless of their respectful silences or more boisterous protests, abound in medical and social service practice.

Likewise, poor communication and negative interpersonal dynamics in teams inevitably hinder effective advocacy with the care seeker while maintaining broader levels of subordination. Attending critically to cases such as Katie's is of general importance because, if she perishes due to insurance neglect, others with similar vulnerabilities are likely to do so as well. History informs us that economically or otherwise socially vulnerable service seekers are frowned upon and often assumed to be responsible for their plight. They may be thought to be weak and irrational when it comes to decisions about financial management, procreation, health in general, and the wellbeing of society.

The caring professions, located "beneath" medical doctors, maintain roles for women which are largely directed by representatives of both genders who tend to share or at least maintain a patriarchal ideology (under the guise of "benevolence") in the highest administrative spheres. Serious ideological, behavioral, and practice contradictions become fostered, as reflected in the statements of female service providers who have followed detrimental state policies. ${ }^{33-34}$

The lack of validation experienced by women then, can have dangerous repercussions when internalized and externalized oppression lead to participation in demeaning practices towards those under our care, and against those who oppose exclusionary bureaucratic policies. If a systems perspective that clarifies the process and impact of compounded social exploitation is not carried out, women and others who challenge the boundaries of established social norms (non-binary, transgender, non-conforming, gay, queer, lesbian) will continue to be targeted for control; they will be blamed for their predicament, and will be more likely to participate in oppressive dynamics rather than transformation. Our tripartite paradigm offers a viable way to improve ethical health care and to address the historical harms that have produced compounded levels of gender de-legitimation and other forms of systemic invisibility. For us to be effective in resolving ethical dilemmas in our teams and in global contexts, we recommend transformative complicity as a primary social work educational praxis (prior to employment by its graduates) and as a central paradigm for transdisciplinary teamwork.

When social workers who are well educated in emancipatory processes are included in medical teams, the congruence between systems-based health provision dynamics, an ethic of care, and the foundational value of beneficence are more likely to impact the service seeker's and team's wellbeing. More importantly, we may generate the power and synergy to humanize our global society. For this to happen, however, critical multidimensional analyses, that promote the courage to act across systems, must be translatable into practical advocacy protocols. They must be carried out by all team members with the service recipient at the forefront. In this sense, a translational science that facilitates the sharing of elite discourses across diverse communities also promotes self-advocacy and empowerment that shatters exclusionary hierarchies. It essentially transforms "clients," and "patients" into therapeutic colleagues with health practitioners in the process of collective empowerment and healing. [] 


\section{REFERENCES}

1. Duntley-Matos R, Shiery M, Ortega RM, Matos Serrano MM, Newberry C, Chapman MM. Promoting LatinX generativity: Cultural humility and transformative complicity through geriatric teams. SAGE Open. 2017 Mar;7(1):2158244016670560.

2. Freire, P. Pedagogía del Oprimido. Siglo XXI. 3ra Edición; 1970.

3. Duntley-Matos, Roxanna I. "Transformative Accomplices: Multicultural Community Organizing in a Transnational Educational Context." PhD diss., 2011.

4. Duntley-Matos R, Arteaga V, García A, Arellano R, Garza R, Ortega RM. "We Always Say: And Then Came The Water..." 1 Flint's Emergent Latinx Capacity Building Journey During the Government-Induced Lead Crisis. J Community Pract. 2017 Oct 2;25(3-4):365-90.

5. Duntley-Matos, Roxanna I. "Representations, power and contradictions: The women's communal movement of Morazán, El Salvador." MA, diss., 1997.

6. Duntley-Matos R. Transformative complicity and cultural humility: de-and re-constructing higher education mentorship for under-represented groups. Qual Sociol. 2014 Dec 1;37(4):443-66.

7. Newberry CL, Duntley-Matos R, Shiery M, Brass E, Beu S. Our homes our health: Humanizing health care through cultural humility, transformative complicity, and empowerment. Ann Behav Sci Med Educ. 2014 Mar 1;20(1):23-8.

8. Duntley-Matos R., Ortega, R. M., Brass E.K., et al. Strengthening Trauma Informed Systems and Child Welfare Services: Cultural Humility, Transformative Complicity and Empowerment through Interdisciplinary Teams. Social Work Challenges in the XXI Century: Perspectives from the USA, Antonio López Peláez ed. Spain. Thomson-Reuters Aranzadi Publisher; 2015.

9. Ortega, R. M., \& Faller, K. C. Training child welfare workers from an intersectional cultural humility perspective: A paradigm shift. Child Welf. 2011; 90(5): 27-29.

10. Tervalon M, Murray-Garcia J. Cultural humility versus cultural competence: A critical distinction in defining physician training outcomes in multicultural education. J Health Care Poor Underserved. 1998;9(2):117-25.

11. Gutierrez LM, Ortega R. Developing methods to empower Latinos: The importance of groups. Soc Work Groups. 1991 Jul 15;14(2):23-43.

12. Harding S. Sciences from below: Feminisms, postcolonialities, and modernities. Duke University Press; 2008 Jun 4.

13. Collins PH. Black feminist thought: Knowledge, consciousness, and the politics of empowerment. Routledge; 2002 Jun 1.

14. Ortega, R.M. \& Garvin, C. Socially Just Practice in Groups: A Social Work Perspective. Sage Publications, 178-179; 2019

15. Sussman RW. There Is No Such Thing as Race. Tech \& Science, Newsweek. Retrieved from http://www. newsweek. com/there-no-such-thing-race-283123. 2014 Nov 8.

16. Xenakis A. Case Study: Truth, Trust, and Team Play. Ann Behav Sci Med Educ. 2015 Mar 1;21(1):44-

17. Wegar K. Adoption, family ideology, and social stigma: Bias in community attitudes, adoption research, and practice. Fam Relat. 2000 Oct;49(4):363-9.

18. Peters K. Politics and patriarchy: barriers to health screening for socially disadvantaged women. Contemp Nurse. 2012 Oct 1;42(2):190-7.

19. Schneider A, Ingram H. Social construction of target populations: Implications for politics and policy. Am Polit Sci Rev. 1993 Jun;87(2):334-47.

20. Metz T, Miller SC. Relational ethics. The International Encyclopedia of Ethics. 2016:1-0.

21. Kessler DA. The basis of the FDA's decision on breast implants. NEJM 1992 Jun 18;326(25):1713-5.

22. Weitz R, Kwan S, editors. The politics of women's bodies: Sexuality, appearance, and behavior. New York: Oxford University Press; 1998 Mar 19.

23. Shim JK. Bio-power and racial, class, and gender formation in biomedical knowledge production. In: Health Care Providers, Institutions, and Patients: Changing Patterns of Care Provision and Care Delivery. Emerald Group Publishing Limited. 2000 May 10;173-195.

24. Alderman AK, Bauer J, Fardo D, Abrahamse P, Pusic A. Understanding the effect of breast augmentation on quality of life: prospective analysis using the BREAST-Q. Plast Reconstr Surg. 2014 Apr 1;133(4):787-95.

25. WebMD. Breast Implants and health insurance. http://www.webmd.com/beauty/breast-implants/breast-implants-andhealth-insurance-facts-to-know. 2005-2015. Retrieved 2/28/15. 
26. Coronil F. Transculturation and the Politics of Theory. In: Cuban counterpoint, tobacco and sugar. Durham, NC: Duke University Press 1995.

27. Tam BY, Findlay LC, Kohen DE. Indigenous families: who do you call family?. J Fam Stud. 2017 Sep 2;23(3):243-59.

28. Robinson-Bailey L. History and ethical principles. University of Wisconsin-Madison Research. https://research.wisc.edu/wp-content/uploads/sites/2/2018/09/History-and-Ethical-Principles-SBE-ID-490.pdf

29. Denham CR. The 3 Ts of leadership engagement: Truth, trust, and teamwork. J Patient Saf. 2006 Sep 1;2(3):162-70.

30. Robison WL, Reeser LC. Ethical decision making in social work. Needham Heights, MA: Allyn and Bacon; 2000.

31. Haiken M. caring.inc. (https://www.caring.com/authors/melanie-haiken); 2007-2015.

32. Hafferty, FW \& Franks R. The hidden curriculum, ethics, teaching and the structure of medical education, Ac Med. 1994; 69(11): 861-871.

33. Frances's $20^{\text {th }}$ Century Slave Trade. Journeyman Pictures. 2003. https://www.youtube.com/watch?v=e_ztVXpqMmc Retrieved 3/12/2016.

34. García, A. La Operación. Latin American Film Project. 1983. https://www.youtube.com/watch?v=RcJr601Uv_s. Accessed on 2/28/2015

\section{FOOT/ENDNOTES}

[a] Observation by Parul Sud, M.D. (Program Director of the Internal Medicine Residency Program at McLaren, Flint, MI) [b] This decision is informed by the first author's experience as a cultural anthropologist in the Women's Communal Movement of the Guerrilla Controlled Zone of Morazán, El Salvador in 1992 (only months after the 12-year Civil War Peace Accords were signed). This was a place and time of social upheaval, spiritual angst, and scarce medical resources ${ }^{2}$ During this period, the impact of Freirean-based literacy circles was evident. The elevated levels of political and philosophical discourse of children, men, and women who had not experienced government sponsored institutional education, was impressive. It became clear that translational science from a Freirean perspective did not end at the level of "understanding" basic levels of science and politics. Rather, it transcended into community critical consciousness in a way that led to political and institutional transformation by and for the benefit of the most historically marginalized.

[c] Multidisciplinary teams, as opposed to transdisciplinary teams, refer to health service providers from different specialties who independently or with minimal team consultation offer their own diagnosis.

d] Dalia Reyes (71-year-old Mexican-American retired insurance company claims administrator): My first thought was that the closed adoption system, which opened the can of worms Katie is facing, was flawed... There should be a way [for] adoptees to obtain their medical history.

[e] Dalia Reyes: I suppose Katie depended on everyone caring for her to know what steps to take for her.... The Insurance company only looking to make the almighty dollar... (My opinion from my dealings with health insurance.)

[f] Dalia Reyes Point taken about the risk of implants, but it should be the woman's choice to take that risk.

[g] Alexandra Isabel Cubero-Matos (21 year-old anthropology student): Are [we] "naive" because [we] lack the medical protection automatically given to men and feel the need to ask?...[1]n the media everything we do is equated to a "female problem" when, by the way, men, have hormones too. This raises the question about what procedures are being dismissed or addressed due to assumptions about gender. It is concerning that [a purportedly] credible government authority, would have such a biased perspective without anything concrete to back up his opinions.

[h] Odeather Hill, LMSW, PhD (73-year-old African American social worker): In February of 2018, I visited my sister while she was hospitalized...The social worker had not ensured [follow-up] medical supplies and home care assistance... When I informed her that I earned a doctorate degree in social work, I immediately was seen by both as [having] authority. Both, the physician and the social worker, accepted my recommendations to ensure appropriate care. I advocated and the outcome was positive... Did skin color play any part in the decision about Katie's care?

[i] Alexandra Isabel Cubero-Matos: I like this part. The questions provide information that facilitates more complex and focused levels of discussion as compared to vague questions that lead to vague answers. 
[.] Daniel Alejandro Cubero-Matos (24 year-old musician and community philosopher): We will not be able to combat color-based persecution until we eliminate the word "racism" from our narratives because it implies "race" as a biological reality.

\section{Conflict of Interest:}

The authors of this article do not have any financial arrangements, organizational affiliations, or other relationships that might constitute a conflict of interest regarding the subject matter of the manuscript. 